\title{
TECNOLOGIA EM DESIGN DE VIDROS CONFORMADOS: UMA PROPOSTA PARA GANHOS EM COMPETITIVIDADE NA INDÚSTRIA 4.0
}

Vicente Cerqueira

Universidade Federal do Rio de Janeiro

vcerqueira@ufrj.br

Resumo: O presente artigo discute aspectos relacionados ao desempenho competitivo da indústria de produtos manufaturados em vidros, a partir da análise dos contextos econômico e tecnológico brasileiro. O objetivo desta pesquisa foi verificar as estruturas produtivas de vidros conformados e propor uma nova dinâmica em sinergia com o cenário produtivo atual e futuro. Especificou-se como prática metodológica o sistema de 'observatório de cenários', com o intuito de verificar o desempenho competitivo da indústria vidreira. Entre os estudos realizados, destacam-se as tecnologias de transformação, cadeia produtiva, logística e mercado, inovação e meio-ambiente entre outros. Durante a pesquisa foi observado que o setor de vidros conformados apresentou perda gradativa de competitividade em relação às outras tecnologias de transformação. Como resultado, é proposta a reestruturação da indústria brasileira de vidros conformados, com a finalidade de oferecer maior flexibilidade à produção de objetos, a partir da ideia da Indústria 4.0.

Palavras-chave: Indústria do vidro, Design de Produtos, Indústria 4.0

\begin{abstract}
This article discusses aspects related to the competitive performance industry of the manufacturing industry in glass, from the analysis of the economic and technology Brazilian context. The objective of this research was to verify the productive structures of shaped glass and propose a new dynamic in synergy with the current production scenario and future. It was specified as a methodological practice the system 'observatory scenarios' to monitor the competitive performance of the glass industry. Among the studies, we highlight the processing technologies, supply chain and, logistics and market, innovation and environment and others. During the research it was found that the glass sector presented gradual loss of competitiveness compared to other technologies. As a result, is proposed the restructuring of the Brazilian glass industry, in order to offer more flexibility to the production of objects from the idea of Industry 4.0.
\end{abstract}

Keywords: Glass industry, Product Design, Industry 4.0 


\section{INTRODUÇÃO}

Desde finais da década de 1980, a indústria vidreira brasileira e mundial apresenta queda de competitividade em diversos segmentos de mercado considerados antes típicos da manufatura em vidros. Parte dessa perda competitiva é decorrente da implementação de novas tecnologias, do desenvolvimento de novos setores produtivos e da falta de percepção sobre novos paradigmas sociais. Porém, este cenário não é comum a todos os segmentos da indústria vidreira, mas em especial ao setor que atuam com a manufatura de bens de consumo por meio das tecnologias de transformação de sopro, compressão e compressão-sopro, destinadas à conformação de produtos acabados em vidros. Enquanto que, o setor de vidros planos tem apresentado índices positivos, dado a percepção diferenciada da estrutura produtiva.

O presente artigo integra uma série de estudos que analisa o desempenho competitivo da indústria de transformação de vidros 'conformados' ou 'funcionais', denominados, equivocadamente, por determinados órgãos de "vidros ocos" e que nas últimas três décadas apresentou índices significativos de queda em competitividade. Salienta-se, entretanto, que este grupo tecnológico é o que apresenta maiores possibilidades de intervenções em design de produtos e de serviços, em decorrência de suas características tecnológicas e mercadológicas.

Logo, o objetivo geral deste trabalho é contextualizar o atual cenário produtivo brasileiro de vidros conformados, em relação às proposições estabelecidas para a quarta revolução industrial, tendo como finalidade o exercício de indicações estratégicas para novas estruturas tecnológicas, econômicas e produtivas, incluindo as atividades em design, visando com isso ampliar a competitividade deste setor e, por conseguinte, estabelecer maior flexibilidade produtiva e integração com o mercado.

Esses estudos tiveram início em 1998, a partir de trabalhos realizados na disciplina de Materiais e Processos de Fabricação, pertencente ao curso de Desenho Industrial/UFRJ, que observaram situações críticas durante as visitas de campo, tais como: máquinas paradas, número reduzido de empregados, desativação de linhas de produtos, fornos trabalhando com capacidade mínima, entre outros aspectos que evidenciavam cenário produtivo desfavorável. Logo, os estudos foram incorporados às pesquisas do Laboratório de Gestão Tecnológica em Design - LABTEC-Design, sob a forma de 'observatório tecnológico', o qual geraram diversos aspectos relacionados ao desempenho da indústria vidreira nacional. Parte desses estudos dão origens a publicações que abordaram os temas: desenvolvimento tecnológico e inovação; e história e evolução de mercado do vidro. No caso deste artigo a temática central esta no contexto da dinâmica competitiva, a partir de um novo cenário produtivo relacionado à ideia da quarta Revolução Industrial ou conforme a Deutsche Akademie der Technikwissenchaften denomina de "Indústria 4.0".

De modo geral, o material vidro sempre foi considerando uma das principais tecnologias de transformação e desfruta de grande prestígio social, pois está presente em vários setores de mercado, tais como: utilidades domésticas, construção civil, embalagens, eletroeletrônicos, automotivo, químico e farmacêutico, entre outros. Este status tecnológico remonta há séculos de acúmulo de conhecimentos e práticas na feitura de produtos com vidros e que até hoje fascinam por suas cores, texturas, transparências e formas. Além disso, este grupo de materiais possui grande importância para a ciência e tecnologias dos materiais, em decorrência de suas características originais e suas propriedades físico-químicas. 
Apesar do amplo domínio de conhecimento científico e tecnológico, a indústria do vidro conformado não conseguiu estabelecer estruturas mais dinâmicas em suas relações produtivas, resultando em certos problemas que resultariam por dificultar seu poder de concorrência.

\section{VIDRO COMO MATERIAL DE TRANSFORMAÇÃO}

A American Society of the International Association for Testing and Materials - ASTM, por meio de seu comitê C-14, define o vidro como "...um material inorgânico de fusão, que se resfriou sem cristalizar... é tipicamente duro e quebradiço. A massa do vidro pode ser colorida ou não, translúcida ou opaca, de acordo com a presença de material cristalino dissolvido na mistura...". Possuindo características amorfas, os vidros apresentam uma condição rígida relacionada ao estado líquido com alta viscosidade, estabelecendo uma distinção, entre o estado sólido dos metais. Os vidros são definidos como materiais inorgânicos em uma condição contínua e análoga ao estado líquido, na qual, como resultado de uma mudança reversível na durante o resfriamento, atingiu um alto grau de viscosidade de modo para fins práticos adquiriu condição de material rígido. Maia (2002:09), por sua vez, comenta que as propriedades dos vidros podem variar continuamente estabelecendo novas fases durante o esfriamento, não tem ponto de fusão definido, apresentam ausência de estrutura cristalina por este motivo não desviam o plano da luz polarizada e conclui indicando que, atualmente, considerase o vidro sob três aspectos análogos, isto é possui propriedades nos estados vítreo, sólido e líquido.

\subsection{Algumas características e propriedades dos vidros}

Para a ciência de materiais, os vidros pertencem ao grupo dos materiais cerâmicos. Na realidade, formam uma espécie de subgrupo, denominado de silicatos, em função da grande concentração de $\mathrm{SiO}(81 \%)$ presente na composição, por outro lado existem vidros que não apresentam Sílica em sua composição, são derivados de óxidos metálicos ou não-metálicos. Diferentemente das cerâmicas, os vidros são materiais que apresentam estrutura amorfa, onde as ligações intermoleculares são organizadas sob a forma de rede, distinguindo-se dos outros materiais por propriedades específicas, isto é, não apresenta porosidade, possui baixo índice de dilatação e condutividade elétrica, é um material com média-alta dureza, apresenta excelentes propriedades óticas e de barreira. Em função dessas características, os vidros se constituem em um dos principiais materiais de transformação.

Os vidros, em geral, são obtidos mediante a mistura de substâncias de origem metálica e não-metálica, tais como: sílica (SiO)- função vitrificante; óxido de cálcio (CaO) estabilizante; soda $\left(\mathrm{Na}_{2} \mathrm{O}\right)$ introduzida através da barilha e objetiva baixar ponto de fusão da sílica; e alumina $\left(\mathrm{Al}_{2} \mathrm{O}_{3}\right)$, introduzida por meio do 'feldspato' oferecendo maior resistência mecânica, ainda pode-se incorporar outras substâncias à massa do vidro para facilitar seu processamento ou mesmo oferecer determinadas características, como por exemplo: o Bórax $\left(\mathrm{B}_{2} \mathrm{O}_{3}\right)$ para vidros refratários, o Cloreto ou Nitrato de Sódio, como afinantes da mistura e óxidos metálicos $\left(\mathrm{Fe}_{2} \mathrm{O}, \mathrm{Cr}_{2} \mathrm{O}_{3}\right.$, etc) como corantes. Além dos componentes básicos que irão conferir propriedades específicas aos vidros, é integrado material reciclado à massa vítrea em quantidades que podem variar de $20 \%$ a $60 \%$. A utilização do vidro reciclado deve-se a redução no consumo de matérias primas básicas e de energia para fundição. 


\subsection{Classificação dos vidros e seus processos}

É observada na literatura a inexistência de sistemas classificatórios plenamente aceitos pela comunidade científica para os vidros. Deste modo, a ASTM dispõe sobre a tipologia dos vidros baseando-se em sua composição química e características físicas, conforme exemplificado na tabela 1 , os tipos de vidros funcionais mais utilizados nos processos de compressão, sopro e compressão-sopro para produção de commodities.

Tabela 1 - Principais vidros aplicado na transformação de objetos utilitários

(Fonte: Elaboração própria com base nos estudos)

\begin{tabular}{|c|c|c|}
\hline Vidros & Características & Aplicações \\
\hline $\begin{array}{l}\text { Alcalinos } \\
\text { (lime glass) }\end{array}$ & $\begin{array}{l}\text { Corresponde ao grupo de vidros mais } \\
\text { utilizado, com aproximadamente } 95 \% \\
\text { de aplicação na indústria. }\end{array}$ & $\begin{array}{l}\text { Embalagens, garrafas, utilidades } \\
\text { domésticas, peças técnicas e vidros } \\
\text { planos para construção civil, mobiliário e } \\
\text { automobilístico; }\end{array}$ \\
\hline $\begin{array}{l}\text { Chumbo } \\
\text { (cristal glass) }\end{array}$ & $\begin{array}{l}\text { São vidros que apresenta grande } \\
\text { concentração de } \mathrm{PbO} \text {, conhecido como } \\
\text { vidro 'cristal'. }\end{array}$ & $\begin{array}{l}\text { Peças laboratoriais, utilidades } \\
\text { domésticas, adornos decorativos e alguns } \\
\text { tipos de vidros planos (texturizado); }\end{array}$ \\
\hline $\begin{array}{l}\text { Boro-Silicato } \\
\text { (Pyrex ou Duran) }\end{array}$ & $\begin{array}{l}\text { Grande resistência a variações de } \\
\text { temperatura (refratário) e ao ataque de } \\
\text { agentes químicos. }\end{array}$ & $\begin{array}{l}\text { Utilidades domésticas, objetos médico- } \\
\text { hospitalares, peças técnicas e } \\
\text { embalagens; }\end{array}$ \\
\hline
\end{tabular}

Também foi observada a falta de consenso quanto às denominações classificatórias às tecnologias de transformação. No entanto, salienta-se que a tecnologia de processo é condicionada pela composição da massa vítrea e as propriedades inerentes. Logo, por conveniência, a tabela 2 mostra os três grupos tecnológicos em relação ao produto final.

Tabela 2 - Grupos Tecnológicos em Vidros e suas aplicabilidades.

(Fonte: Elaboração própria com base nos estudos)

\begin{tabular}{ll}
\hline Processos & Características e aplicações \\
\hline $\begin{array}{l}\text { Processos de vidros } \\
\text { conformados }\end{array}$ & $\begin{array}{l}\text { Grupo tecnológico destinado à moldagem em monoblocos por compressão, } \\
\text { sopro, ou sopro-prensado; tendo como finalidade embalagens, vasilhames, } \\
\text { garrafas, utilidades domésticas, adornos, peças técnicas, copos, panelas, etc. }\end{array}$ \\
\hline $\begin{array}{l}\text { Processos de vidros } \\
\text { planos }\end{array}$ & $\begin{array}{l}\text { Grupo tecnológico de laminação. De acordo com o nível tecnológico, os } \\
\text { processos poderão variar dos mais sofisticados, tais como Fourcolt, Pittsburg, } \\
\text { Libbey-Owens e Float-Glass; até os mais simples obtidos por sistema de } \\
\text { calandragem; tendo como função a produção de vidros planos lisos, de } \\
\text { segurança (temperados e laminados), texturizados, canelados e fotossensíveis. }\end{array}$ \\
\hline Processos de vidros & $\begin{array}{l}\text { Grupo tecnológico de processos especiais que normalmente conjugam técnicas } \\
\text { especiais }\end{array}$ \\
& $\begin{array}{l}\text { térmicas e a vácuo, lâmpadas, produtos eletroeletrônicos que, normalmente, } \\
\text { utilizam massas vítreas especiais às características dos produtos finais. }\end{array}$ \\
\hline
\end{tabular}

\section{METODOLOGIA APLICADA}

A linha metodológica adotada para esta pesquisa seguiu os critérios de 'observatório de cenários', por ser uma sistemática que permite a análise de situações reais e em ambientes turbulentos e complexos, onde a relação tempo adquire importância significativa para a coleta de dados e informações. Foi especificado o intervalo de três anos para coleta de dados e informações por meio do uso de técnicas de observação direta e entrevista/questionário juntos às empresas do setor de vidros 
conformados, sendo cinco localizadas no Rio de Janeiro e três em São Paulo, estados que concentram maior atividade do setor, resultando em14 visitas ao longo de 15 anos de pesquisa. Além disso, foram utilizados dados e informações setoriais extraídos de publicações da ABIVIDRO, da ABRAVIDRO e do Ministério das Minas e Energia - MME Setor de Transformação de Minerais não Metálicos 2012/13 entre outras publicações especializadas. No que se refere à percepção de mercado foram escolhidos duas redes de lojas e duas cadeias de supermercados para verificação de produtos comercializados no varejo, tendo como referência 138 produtos fabricados no Brasil.

Para a pesquisa de campo foram utilizados dois enfoques, sendo um referente às empresas e outro referente ao mercado, a fim de gerar um cenário fidedigno sobre desempenho do setor vidreiro brasileiro de conformados em relação aos dados e informações disponibilizados. Logo, a pesquisa considerou como ambientes de competitividade os seguintes: 1- Ambiente interno (informações diretas): tecnologias e processos, geração ou incorporação de inovações, política ambiental, logística e distribuição, portfólio de produtos e marketshare, entre outras; 2- Ambiente externo (informações indiretas): percepção sobre produtos de vidros; número de produtos em prateleiras; característica de mercado entre outras. Sendo que, neste artigo essas e outras informações estão agrupadas nos descritores básicos de competitividade.

\section{CENÁRIO COMPETITIVO DO VIDRO 2000-2015}

De modo geral, o cenário competitivo industrial se baseia em um conjunto de fatores que extrapolam a ideia de oligopólio, para compor uma matriz complexa que poderá ser alterada por diversos aspectos, influenciando ações tanto no âmbito interno das empresas quanto externo às características de mercado, principalmente, no que tange às questões relacionadas à governança econômico-produtiva. Durante a pesquisa foi observado composições típicos de queda de competitividade, mesmo o setor de vidros conformados apresentando investimentos com certa regularidade no sistema produtivo, principalmente, naqueles referentes à manutenção do rendimento dos fornos de fundição da massa vítrea e na modernização dos processos de transformação. Entretanto, também foi observado, que a indústria vidreira possui algumas 'crenças' no mercado consumidor que poderão induzir a percepções equivocadas, em destaque aquelas relacionadas à crescente demanda de consumo e à qualidade técnica como fidelização.

Esta percepção não apenas limita as ações de mercado, como também evidenciar atenção ao ambiente interno, ou seja, nas Tecnologias Industriais Básicas TIBs por meio da atualização ou adequação de equipamentos (prensas, sopradoras, 'templadores', entre outros recursos) visando o aumento ou manutenção da rentabilidade. A seguir são apresentados os principais descritores que qualificam o desempenho competitivo da indústria brasileira de vidros conformados durante o período correspondente 2000-2015.

\subsection{Cadeia produtiva do vidro}

Vários autores, tais como Slack et al (1999), Fleury \& Fleury (2004), Christofer (2010) entre outros discutem como as relações produtivas interferem na definição estratégicas das empresas. Em sua maioria, convergem em opinião quanto à necessidade de parcerias como forma de ampliar o poder competitivo face à concorrência. 
Sendo um dos principais estudos da gestão de materiais, as cadeias produtivas têm como função básica transformar materiais por meio da incorporação de conhecimentos e valor, tornando-se, um sistema de produção integrado, onde fornecedores e clientes se organizam em níveis hierárquicos distintos, ocasionando, inclusive, alternâncias do poder de governança. Logo, define-se como cadeias produtivas ou de suprimentos o conjunto de operações interconectadas que incluem diversos atores, constituindo-se, em muitos casos, como um sistema em rede, formado por empresas que possuem interdependência logística, através de fluxo produtivo contínuo e direcionado. Outra característica presente às cadeias produtivas esta na capacidade de geração, integração e/ou assimilação de novos paradigmas produtivos, constituindo ações ligadas às questões de fluxo de produtos e serviços como 'oferta'; e de contra-fluxo de informações como 'demanda'.

No caso específico da cadeia do vidro conformado, verifica-se que a concentração produtiva esta na própria empresa vidreira. Isto porque todo o processo produtivo do vidro, desde as etapas iniciais de composição da massa vítrea até a transformação e acabamento dos produtos finais fica a cargo da própria empresa vidreira. Esta verticalização produtiva, não significa, entretanto, poder de governança, mas controle sobre as 'TIBs' envolvidas no processo. A figura 01 exemplifica a estrutura básica de fabricação do vidro prensado destinada à produção de diversos utensílios.

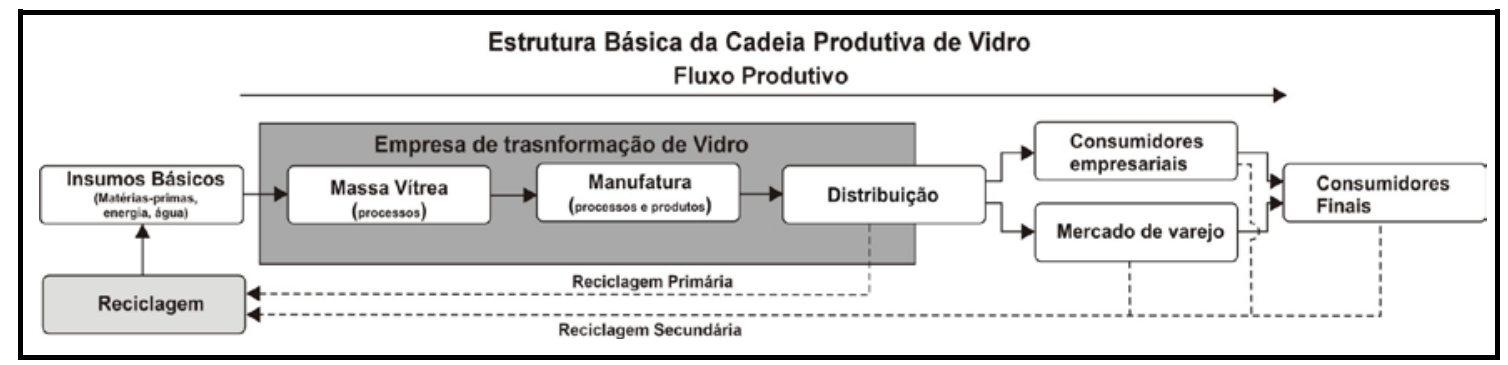

Figura 01 - Fluxo produtivo simplificado para o vidro prensado

(Fonte: elaboração própria, 2012)

\subsection{Mercado de vidros conformados}

Os estudos sobre o desempenho econômico e mercadológico da indústria brasileira do vidro conformado, em sua maioria, são constituídos a partir de pesquisas sobre o desempenho do vidro plano. O máximo em detalhamento sobre o setor de conformados é apresentado pela ABIVIDRO (2008), que os agrupa em apenas três os segmentos econômicos, tais sejam: embalagens (garrafas, potes, frascos, etc.); utilidades domésticas (pratos, travessas, panelas, copos, tigelas, etc.); e artigos técnicos (automotivos, eletrodomésticos, laboratório, etc.) - demonstrado na figura 02.

De certo que este modelo de análise dificulta a percepção quanto ao efetivo desempenho de mercado da indústria vidreira em nichos específicos de mercado. Esses estudos, entretanto, servem para demonstrar a capacidade instalada de vidro no Brasil, em comparação com outros países de expressiva atividade vidreira, tais como: EUA, França, Inglaterra, Itália e china.

Complementando os estudos, a pesquisa identificou no setor de varejo que os produtos em vidros apresentaram uma queda geral de $12 \%$, independente do segmento de mercado no período apurado, confirmando os resultados apresentados por estudos setoriais. 


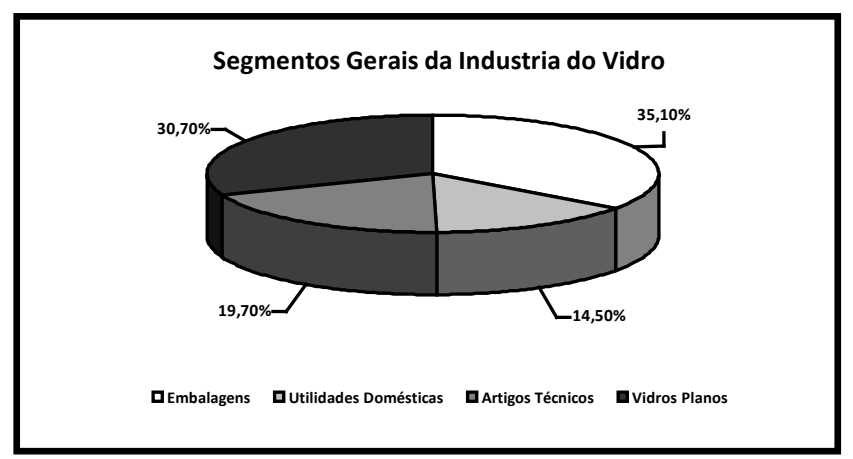

Figura 02-Segmentação de mercado da indústria do vidro no Brasil (Fonte: ABIVIDRO, 2008)

Destaca-se que entre os anos de 2003 e 2006 a queda do setor foi bastante acentuada (21,6\%). Não há uma explicação plausível para esta queda, já que a economia em 2006 estava favorável à atividade industrial e o Dólar com patamares baixos. Logo, a justificativa mais aceita era a perda de rentabilidade do setor em face a outras tecnologias. Observa-se no gráfico (figura 03) que dentre os segmentos que apresentaram leve sinal de reação, o de embalagens é o mais expressivo, 'puxado', principalmente, pelo setor de garrafas para cervejarias. Enquanto os outros segmentos continuam oscilando de maneira negativa. Apesar desta queda em número de itens e na transformação do vidro, foi verificado que o setor de vidros conformados apresentou crescimento no faturamento na última década de, aproximadamente, $\mathrm{R} \$$ 2.8 milhões (ABIVIDRO, 2008/09), correspondendo a um crescimento de 5.3\%/aa. Este crescimento foi derivado do aumento de exportações para o Mercosul e investimentos em programas de qualidade, a fim de reduzir as perdas e aumentar a eficiência energética.

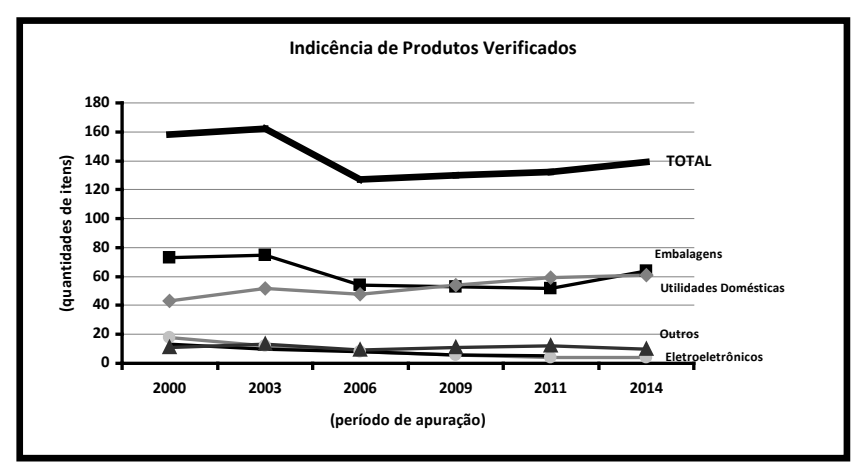

Figura 03- Percepção de Produtos manufaturados em vidro

(Fonte: Elaboração própria, 2014)

\subsubsection{Produção e capacidade instalada}

Segundo dados da MME (2012/13), grande parte da produção vidreira brasileira concentra-se no mercado interno, apenas $7 \%$ da produção de vidros conformados destina-se à exportação e grande parte é comercializada para Argentina, México e Colômbia. Verifica-se, entretanto, que na última década a balança comercial brasileira em produtos de vidro mostrou-se positiva com saldo médio de $R \$ 16.7$ milhões, sendo que nos últimos anos a balança ficou negativa, dado à queda de produção de interna e ao aumento de custos de insumos básicos. 
A capacidade instalada no setor de vidros é mensurada pela quantidade de vidros em toneladas colocados no mercado, ao contrário de outros segmentos produtivos que fazem menção aos recursos disponíveis para produção. A figura 05 mostra a capacidade instalada da indústria brasileira, a partir dos segmentos de mercado e em relação comparativa entre vidros planos e conformados. Destaca-se, entretanto, que os valores concernentes aos dois últimos períodos de apuração (2011 e 2014) são projeções e estimativas, ainda não consolidadas.

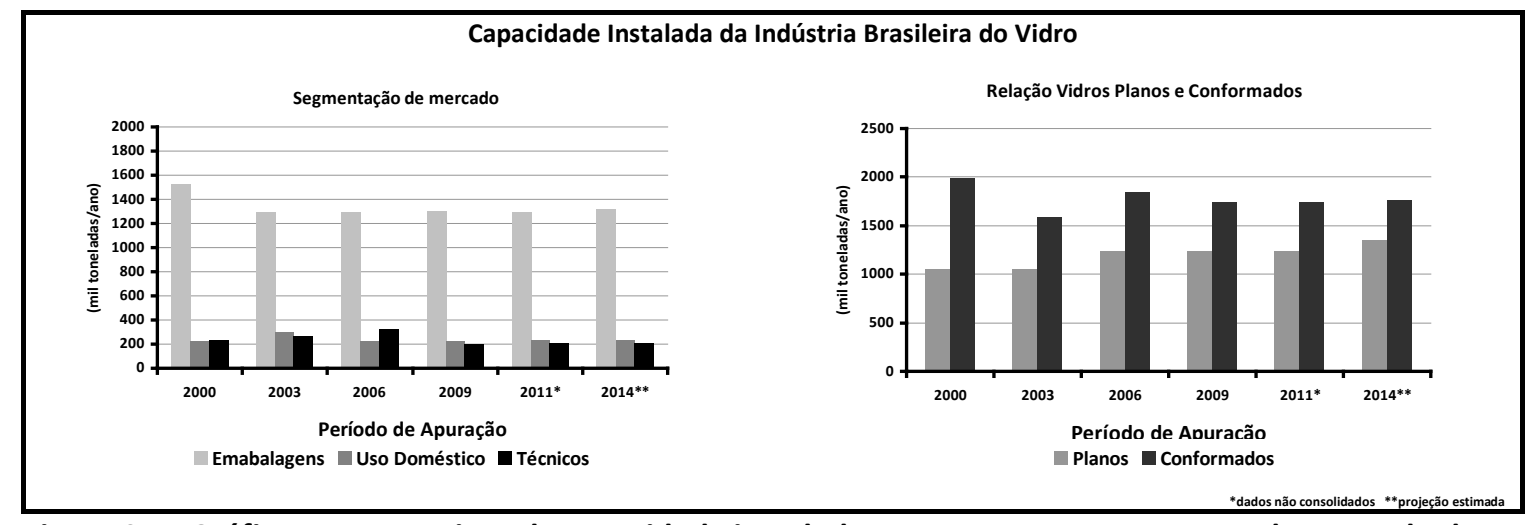

Figura 05 - Gráficos comparativos da capacidade instalada entre segmentos e setores de mercado de vidro (Fonte: a partir de dados da ABIVIDRO, 2008)

\subsubsection{Tecnologias entrantes}

Nas últimas décadas a indústria do vidro foi submetida a dois grandes impactos tecnológicos que afetaram diretamente seu desempenho competitivo. O primeiro impacto foi o desenvolvimento de novas tecnologias relacionadas às ligas metálicas ferrosas e não-ferrosas, nos setores de embalagens de bebidas e de alimentos. A implantação de novos processos galvânicos e o aperfeiçoamento de processos de impressão (rotogravura e flexografia) permitiu maior qualidade técnica às embalagens, permitindo, assim, novos atributos às ações de promoção de vendas. Os ganhos em produtividade, em logística, em automação e, por consequência redução de custos, fizeram que muitas empresas a montante optassem pela mudança tecnológica, abandonando as embalagens de vidro que eram pouco rentáveis.

O segundo impacto foi o grande desenvolvimento dos polímeros termoplásticos, a partir da década de 1980. Este grupo de materiais, além de apresentar forte apelo estético é extremamente leve, possui grande rentabilidade (automação e baixo custo) e em sua maioria apresenta boa tenacidade. Ao contrário das ligas metálicas, os termoplásticos não se restringiram ao segmento de embalagens, conquistaram, também, outros segmentos, tais como: eletrodomésticos (linha branca e eletrônicos) e utilidades domésticas. Além desses, competem diretamente com o vidro nos segmentos de peças técnicas e laboratoriais. Essas substituições se devem, principalmente, ao menor peso transportado e a redução de perdas em estoque, que impactam diretamente nos custos finais do produto. Esse conjunto de tecnologias impôs à indústria vidreira perda que variam entre $60 \%$ a $85 \%$ de segmentos de mercado e em alguns casos a substituição total de produtos em vidro.

\subsubsection{Questões ambientais e de energia.}

Os vidros são materiais inertes e facilmente reciclados quando ocorre a chamada reciclagem primária. A maioria dos vidros qualificados como commodities 
utilizam de $20 \%$ a $30 \%$ de vidro reciclado, pois este entra na mistura da massa vítrea constituindo-se como uma espécie de fundente, pois se liquefaz com menos energia térmica. Grande parte das matérias-primas utilizadas na fabricação da massa vítrea não chegam a produzir significativos impactos ambientais e são abundantes na natureza, porém é um material que se descartado na natureza é poluente e inseguro se manuseado incorretamente.

O principal problema ambiental enfrentado pela a indústria do vidro, tanto no Brasil como no mundo é o consumo de energia aplicado durante o processo produtivo. O processo de fabricação do vidro conformado é dependente de dois tipos de energia: 1- Energia térmica utilizada nos fornos para produção da massa vítrea, proveniente do GLP; e 2- na energia elétrica utilizada para movimentar máquinas e instalações transformadoras. As elevações constantes no preço do GLP e da eletricidade condicionou a energia ao principal insumo do setor vidreiro, inibido investimentos em outros fatores de produção, assim como em novas linhas de produtos. Esses modais de energia não emitem gases formadores do efeito estufa - GEE. Informações coletadas pela ABRAVIDRO (2014) destacam que algumas empresas do setor estudam outras modalidades de geração de energia para alimentação dos fornos, principalmente, 0 uso do carvão coque. Porém, as estimativas quanto à emissão de GEE, ainda não foram mensuradas e isto poderá ser um retrocesso ambiental do setor.

\subsubsection{Política de inovação}

Além das questões que envolvem alterações na utilização da energia, a indústria vidreira, de modo geral, apresenta um comportamento gerencial conservador em seus investimentos, focando, principalmente, na modernização dos processos produtivos com vistas à redução de insumos e custos operacionais. A tabela 02 mostra as características das inovações realizadas normalmente pelo setor vidreiro.

Tabela 03 - Características das inovações no setor de vidros conformados (Fonte: Elaboração própria, 2015)

\begin{tabular}{|c|c|}
\hline Tipo de Inovação & Características da Inovação \\
\hline $\begin{array}{l}\text { Inovação em } \\
\text { Processo }\end{array}$ & $\begin{array}{l}\text { Corresponde ao foco principal da indústria vidreira com a finalidade de otimizar ao } \\
\text { máximo os processos produtivos com ações de modernização baseadas na } \\
\text { mecanização, visando o aumento da qualidade e eficiência tecnológica; }\end{array}$ \\
\hline $\begin{array}{l}\text { Inovação em } \\
\text { Produto }\end{array}$ & $\begin{array}{l}\text { Ocorrem em menor número e estão relacionadas à dinâmica de segmentos } \\
\text { específicos de mercado e se concentram nas atividades projetivas de moldes e } \\
\text { matrizes. Alguns casos estudados são relatados investimentos em design; }\end{array}$ \\
\hline $\begin{array}{l}\text { Inovação em } \\
\text { Serviço }\end{array}$ & $\begin{array}{l}\text { Está presente em grande parte da indústria de transformação do vidro e } \\
\text { encontram-se apoiada nas ações de marketing (vendas), mas com pouca } \\
\text { intervenção tecnológica; }\end{array}$ \\
\hline
\end{tabular}

Foi verificado que as empresas pesquisadas possuem setores técnicos que se assemelham em atividades aos departamentos de Pesquisa e Desenvolvimento (P\&D). São setores de projetos (e/ou design), que atuam com produtos e ferramentaria; setores mecânicos, destinados ao aperfeiçoamento e manutenção do sistema de transformação; setores químicos e de matéria-prima, com a finalidade de controle da massa vítrea; além de setores de marketing e ou de venda, que atuam com promoção, entre outras ações. Apesar dos investimentos feitos pelas amostras, observa-se certa falta de sinergia entre os setores empresariais, fazendo com que as atividades de inovação sejam descontinuas e, em muitos casos, desconexas uma com as atividades 
projetivas. Nas últimas décadas os investimentos se concentraram em processos. Porém, foram observadas algumas iniciativas relacionadas ao segmento de embalagens, tais como as garrafas Thick Neck e a incorporação de outras tecnologias (metais, plásticos e elastômeros) em produtos acabados para agregar valor.

\section{RESULTADOS E DISCUSSÕES}

Os estudos apresentados ao longo desses quinze anos evidenciaram que a indústria brasileira do vidro conformado, apresentou 'crescimento negativo'. Este fato resulta, em parte, das condições processuais apresentadas pela maioria das empresas, associado a um comportamento gestor baseado no ambiente interno. Observou-se que o sistema de produção do vidro conformado, ainda mantém laços com sistemas de produção semelhantes às corporações de ofício pré-industriais em empresas de médio-porte, atuantes com produtos específicos ou pseudo-commodities. Assim como ligações com o estágio tecnológico da segunda fase da Revolução Industrial para empresas de grande porte que atuam com larga escala de produção em commodities.

O foco no domínio do processo produtivo ignorou as ameaçadas tecnológicas surgidas nas últimas décadas do século $\mathrm{XX}$ e que acabariam por conquistar nichos de mercados antes considerados típicos da indústria vidreira. A verticalização produtiva, o excesso de confiança na tecnologia, a crenças no aumento de demandas crescentes e a concentração em grandes volumes de produção, induziram a interpretações equivocadas de mercado, que aliadas a determinadas situações econômicas condicionaram a indústria de vidros conformados á certas fragilidades competitivas. Fato que não é percebido no setor do vidro plano, que ao estabelecer parcerias ou mesmo terceirizar etapas do processo, favoreceu o surgimento de empresas convertedoras e novos transformadores, a partir da oferta de lâminas/placas de vidro e/ou da transferência de know-how tecnológico.

Logo, não seria exagero em afirmar (ou talvez confirmar) que a indústria de vidros conformados passa por uma crise de gestão, pois se observou um cenário com indicativos desfavoráveis. Como exemplo, durante o período de estudo três empresas no Rio de Janeiro encerram suas atividades com a manufatura de vidros em detrimento de outras tecnologias ou outros fatores. Deste modo, considera-se que o domínio tecnológico e a capacidade produtiva existente não foram suficientes para estabelecer sinergia com os novos paradigmas econômicos e sociais, principalmente, nos segmentos de larga escala. Em decorrência deste cenário, foram analisadas as proposições da "Indústria 4.0" como luz para possíveis adequações no perfil produtivo da indústria vidreira de conformados.

A ideia da quarta Revolução Industrial corresponde, na realidade, à convergência de uma série de proposições científicas e tecnológicas iniciadas nas últimas décadas do século XX e que tiveram como bases o avanço da computação, a conscientização ambiental, a plena automação da produção e a geração de novos atributos profissionais, tendo como finalidade oferecer maior dinamismo à manufatura e adequabilidade aos grupos sociais por meio de novos conceitos produtivos, onde grande parte do ambiente de negócios estará localizada na internet (internet of things). Entre as várias proposições presentes na Indústria 4.0 a que melhor se adequa à indústria vidreira esta baseada na segmentação ou redistribuição produtiva, a exemplo de outros setores industriais. Assim como a "manufatura aditiva" também poderá contribuir significativamente para melhorar a dinâmica do setor. Esta 
segmentação possibilitará maior flexibilidade na produção, incentivando, inclusive, atividades em inovação mais condizentes com as expectativas de grupos sociais, isto porque, favorecerá o surgimento de novas empresas à montante que atuarão mais próximas aos consumidores, conforme esquematizada na figura 05.

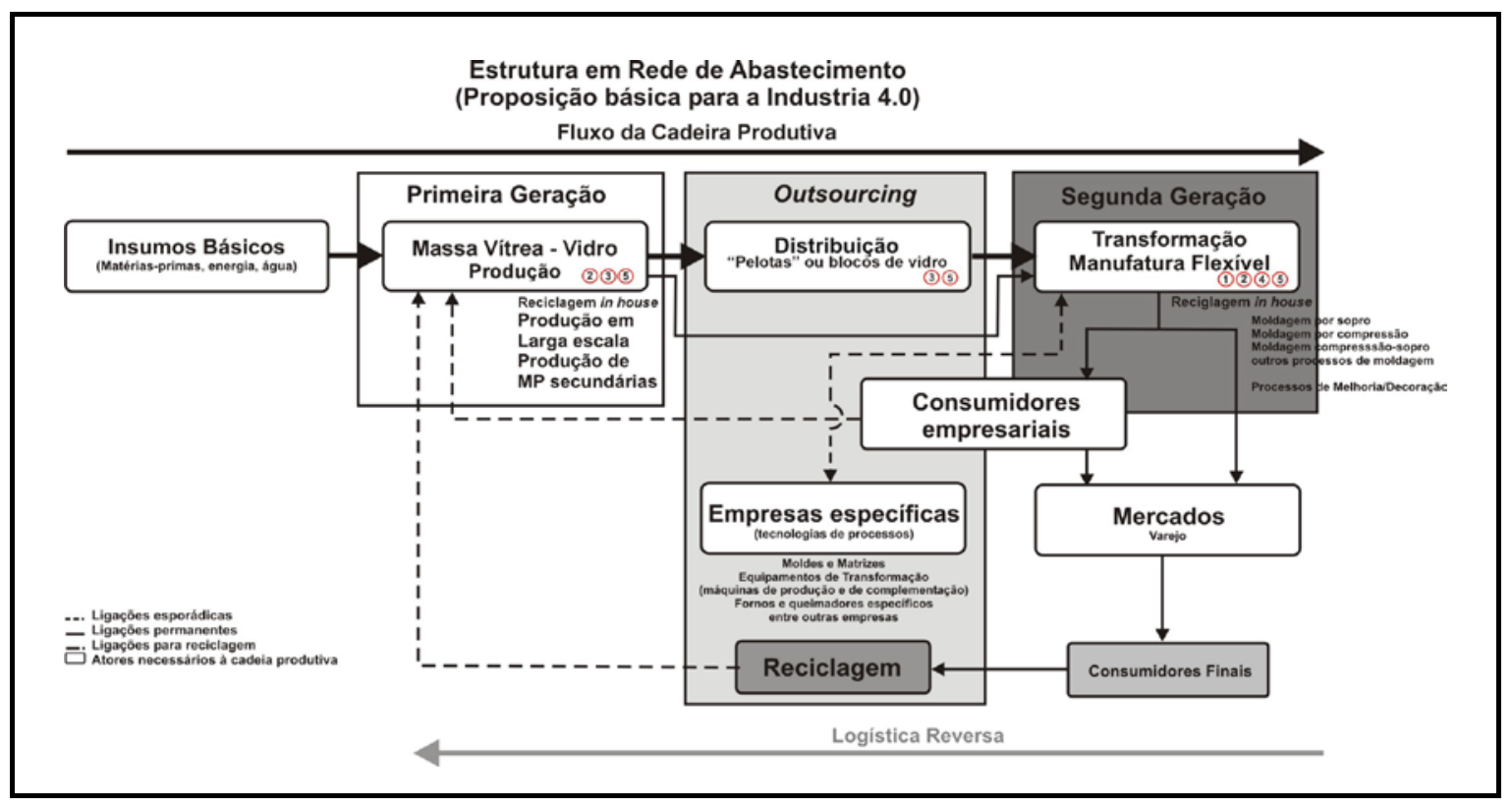

Figura 05- Estrutura proposta para a cadeia produtiva do vidro conformado na indústria 4.0

(Fonte: elaboração própria, 2015)

De modo geral esta proposta consiste em segmentar as atividades produtivas série, possibilitando a ocorrência de novos atores com competências produtivas específicas (design, engenharia, produção, logística e reciclagem). Deste modo, as questões entre oferta e demanda serão alimentadas constantemente, a partir da constituição de cenários, onde as informações são processadas e solucionadas de maneira paralela e não-linear, possibilitando, inclusive, a incorporação de novas tecnologias, tais como a manufatura aditiva.

\section{CONCLUSÕES}

Em 2011, o Governo brasileiro apresentou o programa de desenvolvimento da competitividade da industrial nacional face às constantes perdas no cenário internacional. Entre as metas estabelecidas destacam-se duas: o aumento da produtividade geral, a partir do aumento eficiência tecnológica; e a implantação de políticas de inovação, baseadas no desenvolvimento científico. Porém, as metas propostas não entraram em vigor de modo efetivo. Pelo contrário, deram lugar a uma nova crise econômico-produtiva. E os incentivos e recursos não se converteram em ganhos econômicos, assim como o domínio científico e tecnológico não foram suficientes para dar respostas a contento para o mercado, submetendo a indústria vidreira de conformados à depreciação tecnológica.

Por mais "enxutas" que sejam as empresas, há um dicotomia entre os investimentos gerais em inovação com os novos paradigmas produtos. Enquanto a mecanização ainda é a voga da indústria vidreira a sociedade apresenta outras expectativas de mercado, isto é produtos em menor escala e com mais valor. 
É obvio que o material vidro não deixará de existir, muito pelo contrario. $\mathrm{Na}$ Indústria 4.0 sua utilização estará condicionada às especificidades tecnológicas ou mais adequada às expectativas dos consumidores, coexistindo com produtos commodities feitos em larga escala em sistemas automatizados. No entanto, a proposta mais condizente para a indústria vidreira em futuro próximo esta da dissociação da produção da matéria-prima vidro da transformação em produtos. Ou seja, a partir de usinas de processamento e distribuição da massa vítrea, empresas de pequeno e médio porte, localizadas próximas aos consumidores possibilitaram maior flexibilidade produtiva e estarão mais dispostas às inovações em produtos, inclusive, com novas tecnológicas de transformação. Vidros halogenetos, vidros usináveis, vidros flexíveis, compósitos metálicos com vidro, entre outros e impulsionaram novos processos produtivos, em menor escala dada às suas especificidades tecnológicas e de mercado. Por outro lado, os vidros funcionais recuperarão seu status original de um material com grandes qualidades plásticas em sistema de produção limitada ou em escopo.

Por fim reafirmam-se três pontos: no atual contexto de produtivo, o poder competitivo não está apenas no domínio tecnológico, mas na capacidade de integração de conhecimentos; o desempenho dos setores industriais baseia-se nas relações criadas entre os diversos atores, por meio de uma gestão integrada; e na capacidade das empresas em reconhecer as expectativas do mercado, como aspecto fundamental para a definição estratégica.

\section{AGRADECIMENTOS}

Ao CNPq/UFRJ - Programa Institucional de Bolsas de Iniciação Científica/PIBIC;

Às Empresas que gentilmente aceitaram participar da pesquisa;

Aos Alunos do Curso de Desenho Industrial/UFRJ que participaram das visitas técnicas;

\section{REFERÊNCIAS}

ANUÁRIO ABIVIDRO 2008. Associação Brasileira da Indústria do Vidro. Disponível em http://www.abividro.org.br/anuario-abividro/2008. Acesso em 09/07/2009.

ANUÁRIO ABRAVIDRO 2014. Associação Brasileira de Distribuidores e Processadores de Vidros Planos. Disponível em http://abravidro.org.br/mercado/panoramaabravidro/2014; Acesso em 12/04/2015.

ARNOLD, J. Introduction to material management. New Jersey: Prentice-Hall, 1988.

ROSA, S.; Cosenza, J.; BARROSO, D. Considerações sobre a Indústria do Vidro no

Brasil. BNDES Setorial, Rio de Janeiro, no. 26, p. 101-138, set. 2007;

CERQUEIRA, V. Marketing strategy and the formation of competency in the Brazilian industry glasses. In: Anais XXII International Congress of Glass - ICG 2010. Salvador: UFSCar/ABIVIDRO, 2010.

CERQUEIRA, V. Design for Glass: A study of the historical relationship of production with new social paradigms. In: Anais $8^{\text {th }}$ Conference ICDHS 2012. São Paulo: USP/Edgar Blucher, 2012.

CHRISTOFER, M. Logística e o gerenciamento da cadeia de suprimentos. São Paulo: Cengage Learning, 2010. 
FLEURY, A.; FLEURY, M. Estratégias empresariais e formação de competências. São Paulo: Atlas, 2004

MAIA, S. O Vidro e sua Fabricação. Rio de janeiro: Interciência, 2003.

KAGERMANN, H; WAHLSHER, W; HELBIG, J. Recommendations for implementing the strategic initiative industrie 4.0. FMER/German, 2013.

SLACK, N. et al. Administração da produção. São Paulo: Atlas, 1999.

SMITH, William F. Principles of Materials Science and Enginneering. New York, McGraw-Hill, 1996.

_. _. O Vidro: Sua História e Fabricação. São Paulo: Blindex, 2002. 